\title{
Entre el cristianismo y la política: la incidencia política para la paz en la ideología de la Iglesia Cristiana Menonita en Colombia
}

Between Christianity and Politics: The Political Impact for Peace in the Ideology of the Mennonite Christian Church in Colombia

RESUMEN

El presente artículo presenta los resultados de una investigación sobre la postura ideológica de la Iglesia Cristiana Menonita frente al proceso de paz en Colombia. Mediante un análisis de los discursos orales de sus integrantes y sus publicaciones, abordo su fundamentación doctrinal, su propuesta de participación política y sus estrategias de formación para la paz. Se trata de un estudio de caso que acude a las entrevistas semiestructuradas y al análisis de textos. Concluyo que los menonitas, desde una postura no partidista, quieren incidir políticamente en la construcción de paz en Colombia.

Palabras clave: política, religión, paz, cristianismo menonita, educación para la paz.

\section{ABstract \\ This article presents the results of research into the ideological position of the Mennonite Christian Church in the face of the peace process in Colombia. Through an analysis of the oral speeches of its members and its publications, its doctrinal foundation, its proposal for political participation}

Yenny Natalia

Ramírez-Bravo

Licenciada en Pedagogía Infantil, Magíster en Ciencias Sociales. Docente adscrita a la Facultad de Ciencias de la Educación, de la Universidad Tecnológica de Pereira.

\ynramirez@utp.edu.co

(1) ORCID: 0000-0002-2446-944X

ڤs Google Scholar 
and its strategies for peace formation are addressed. This is a case study that resorts to semi-structured interviews and text analysis. In conclusion, Mennonites, from a nonpartisan stance, want to influence politically the construction of peace in Colombia.

Keywords: politics, religion, peace, Mennonite Christianity, education for peace.

\section{Introducción}

E ste artículo parte de la investigación referida a la ideología pacifista de la Iglesia Cristiana Menonita, abordada desde la relación existente entre el cristianismo y la política, la cual considera que la religión funciona como aparato ideológico de las comunidades de personas, que les permite una comprensión particular del mundo, y que implica una incidencia política supeditada a sus propios planteamientos doctrinales y teológicos. El estudio surgió en el marco de la histórica votación negativa de las iglesias cristianas protestantes en el plebiscito que buscaba refrendar los acuerdos de paz, establecidos entre el gobierno colombiano y la guerrilla de las FARC-EP hacia el año 2016, reconociendo como caso atípico el de la Iglesia Cristiana Menonita, por haber mostrado su participación a favor de los acuerdos, y tener una propuesta anticipada para la construcción de paz en el país.

El suceso mencionado lleva a retomar la discusión sobre la relación existente entre la religión y la política, y cómo dicha relación tiene efectos para el país en términos de la consolidación de un estado democrático, laico y moderno. En el caso puntual, dicha relación afecta los procesos de construcción de paz en el país, a partir de la incidencia política y la alienación de las iglesias cristianas protestantes y evangélicas a determinados partidos políticos, especialmente de derecha y extrema derecha, que han mostrado su desaprobación a los acuerdos de paz en la mayoría de los casos, y que se amparan en la idea de protección a la familia tradicional, siendo este último un argumento que provoca afinidad entre ciertas iglesias, particularmente las de corte neopentecostal, con las políticas de derecha.

El objetivo principal de esta investigación estuvo orientado a analizar la postura ideológica de la Iglesia Cristiana Menonita frente al tema de la paz en Colombia, articulando su fundamentación doctrinal, su 
propuesta de participación política y sus estrategias de formación para la paz, a través de los discursos orales y escritos. El ejercicio investigativo puede resultar de interés en el campo de las ciencias sociales porque permite reconocer cómo los fundamentos doctrinales y teológicos de una iglesia cristiana, afectan la propuesta de participación política por la paz en el país, desde la construcción de un concepto de paz y de incidencia política, y cómo se plantean estrategias pedagógicas para la promoción de la educación para la paz.

En el marco de la investigación cualitativa, el objeto fue abordado a través de la metodología de estudio de caso, valiéndose de estrategias de recolección de información como la entrevista semiestructurada y el análisis de textos. La población que participó de la entrevista corresponde a líderes y miembros de la Iglesia Cristiana Menonita, y personal de la asociación cristiana menonita para la justicia, paz, y acción no violenta "Justapaz", ocho personas en total, ubicadas en al menos cinco municipios colombianos; además se hizo el análisis de 11 textos correspondientes a documentos oficiales, cartillas conmemorativas, sistematizaciones de experiencias y guías de formación, en todos los casos publicados por la Iglesia Cristiana Menonita y Justapaz. La intención principal, se centra en motivar la investigación en ciencias sociales a la lectura de los escenarios religiosos, que no pueden descuidarse o catalogarse de obsoletos, dado que aún siguen en vigencia cuando se intentan asimilar las implicaciones políticas que tiene la vivencia de la fe y la espiritualidad, sobre todo cuando de aportar a la consolidación de la paz se trata.

\section{Planteamiento del problema y justificación: La participación de las iglesias cristianas protestantes y evangélicas en el plebiscito por la paz}

La historia de los últimos 50 años en Colombia, se ha contado desde escenarios de violencia directa, simbólica y cultural. La presencia de grupos armados subversivos, la inversión cuantiosa en defensa nacional y el legado del narcotráfico, han afectado fuertemente los procesos de construcción de paz en el país. Hacia el 2016, se hizo público un acuerdo de paz entre el gobierno colombiano y las guerrillas de las FARC-EP; un acuerdo que permitiría pasar la hoja y empezar un nuevo capítulo en la historia colombiana, no porque fuera el fin del conflicto sino porque era el primer paso en la formación de una paz imperfecta, sacando a uno de los tantos grupos involucrados en el conflicto y evitando la muerte de miles de personas al año. El gobierno, con el ánimo de hacer más participativo el proceso de construcción de paz, sometió los acuerdos a un plebiscito que se efectuó el 2 de octubre de 2016, y que pretendía una refrendación apoyada por la masa de colombianos. Sin embargo, y en contradicción con 
lo que se esperaba ganó el no, con un margen muy estrecho, que llevó a cuestionarse sobre la participación política de los colombianos y lo que esperaban del país en adelante.

Un hecho que fue aún más sorpresivo, fue la participación de gran cantidad de iglesias cristianas protestantes y evangélicas involucradas en la campaña liderada por el expresidente Álvaro Uribe Vélez, quien se apoyó en mega iglesias de corte neopentecostal como la Misión Carismática Internacional, argumentando que los acuerdos promovían la ideología de género y atentaban contra la idea de familia tradicional; este suceso motivó a muchas más iglesias a unirse por el no durante las votaciones. Además de lo contradictorio que pareció esta decisión de las iglesias que profesan seguir el evangelio del amor y el perdón de Jesús, se pudo reconocer que las comunidades cristianas protestantes se convertían en fuerza electoral, y que por lo tanto su interés y participación en los asuntos políticos del país se hacían cada vez más significativos.

Lo anterior era algo que se venía hablando en la investigación social con mucha antelación, haciendo notar el asunto de la proliferación de las iglesias cristianas protestantes en el territorio colombiano, modificando el mapa religioso y las formas de participación política de los miembros de las congregaciones. Las iglesias se han prestado como escenarios no solo de eventos relacionados a la fe, sino como plataformas para la campaña de candidatos políticos, y promoción de sus ideas y propuestas, abriendo el interrogante si realmente las propuestas políticas son las que movilizan a los cristianos a un lado u otro en las balanzas electorales, o si existe afiliación a los partidos de derecha y extrema derecha en el país, porque les permite conservar cierto acceso al poder y a lo que esto implica en un país inequitativo como Colombia.

Sin embargo, en medio de las tensiones que se generaron en la población cristiana colombiana, se pudieron reconocer algunos casos atípicos, quienes hicieron pública su posición por el sí en el plebiscito por la paz, entre estos los casos de iglesias cristianas históricas como las presbiterianas y anabaptistas. Al final de la declaración de la iglesia presbiteriana se lee:

Como un acto de fe, el Consejo del Sínodo de la Iglesia Presbiteriana de Colombia, reunido en Barranquilla el 5 de septiembre de 2016 acordó por unanimidad respaldar el Sí a la refrendación de los acuerdos de La Habana a través de la herramienta constitucional del Plebiscito, como un camino posible en la construcción de la paz, que 
todavía sigue siendo incompleto e imperfecto pero que apoyamos decididamente. (Consejo Latinoamericano de Iglesias, 2016)

La iglesia presbiteriana además argumentó que a pesar de los muchos ataques que la iglesia cristiana ha recibido en Colombia por la guerra, cómo muchos líderes cristianos han sido asesinados y se han tenido que desarrollar diversas estrategias para tratar de recuperar lo que la guerra les quitó a los habitantes del país, el perdón es la forma de construir un mejor futuro y esto es fundamental en el evangelio de Jesucristo. También la iglesia menonita de tradición anabaptista presentó sus siete manifiestos que sostuvieron la idea de apoyar al plebiscito, uno de ellos menciona:

Entendemos que los documentos de los acuerdos son extensos y que hay puntos en que las personas pueden estar a favor o en contra. Aunque los acuerdos no son perfectos, nos identificamos con la frase que se ha acunado recientemente, la cual sostiene: "que es mejor una paz imperfecta que una guerra perpetua". (Consejo Latinoamericano de Iglesias, 2016)

De este modo, se pudo reconocer que para algunas iglesias cristianas el tema de la paz guardaba relación con sus propios intereses como comunidades religiosas, encontrando que eran iglesias que venían abordando el asunto con anterioridad al surgimiento de los acuerdos de paz y el plebiscito. Este interés fue evidente a través de entidades como el Consejo Mundial de Iglesias, y en el caso de Colombia Cedecol (Consejo Evangélico Colombiano), los cuales han sido enfáticos en su interés de ser parte activa en procesos generadores de paz, argumentando que uno de los instrumentos más útiles es educar a sus integrantes bajo principios cristianos y valores ciudadanos que promueven la convivencia pacífica, el respeto al otro, y sobre todo el amor como mandamiento principal del cristianismo, acciones que pueden ser enseñadas y trasmitidas a los miembros de las iglesias (Cedecol, 2006; Consejo Mundial de Iglesias, 2009).

De los dos casos atípicos mencionados, se reconoce la Iglesia Cristiana Menonita como una organización religiosa que ha puesto dentro de sus principios doctrinales el asunto de la paz como tema trasversal a todo lo que desarrolla. La paz en sus propios términos es más que un legado del evangelio de Jesucristo, un llamado a ser un pueblo de paz y hacedor de la paz a través de la reconciliación. En este punto es que surge el interés por reconocer cómo una iglesia cristiana desde su visión bíblica, teológica y política le hace una apuesta a la paz en el país, y a pesar de no 
tener, como en el caso de las iglesias pentecostales y neopentecostales, un crecimiento acelerado, ha puesto su énfasis en la formación del pensamiento crítico de las personas en asuntos sociales y políticos como la paz.

\section{Metodología}

El estudio se ubicó dentro de la investigación cualitativa, la cual Deslauries (2004), identifica como aquella "que produce y analiza los datos descriptivos, como las palabras escritas o dichas, y el comportamiento observable de las personas" (p. 6). Dado que el objetivo de la investigación estaba orientado hacia el análisis de un fenómeno de la sociedad, correspondiente a la participación política de una iglesia cristiana respecto a la construcción de paz en el país, este tipo de investigación, la cualitativa, se constituye como una metodología flexible al someterse al objeto de estudio, reconociendo sus límites dentro de lo real y sus características particulares; la investigación se desarrolló a través del estudio de caso, el cual se define como "un método de investigación cualitativa que se ha utilizado ampliamente para comprender en profundidad la realidad social" (Barrio et al., 2015, p. 2).

El propósito fundamental del método de estudio de caso es comprender la particularidad del caso en cuestión (Barrio et al., 2015), por lo que para lograrlo se dio un acercamiento importante a la comunidad de fe identificada, a través de estrategias de recolección de información como la entrevista semiestructurada y rejillas de análisis de texto, buscando comprender los motivos que subyacen a su trabajo por la paz en Colombia, bajo el cuestionamiento de cómo y por qué sucede (Martínez, 2011). Una de las críticas que recibe comúnmente el método de estudio de caso, es la imposibilidad de hacer generalizaciones a partir de las particularidades del caso analizado, por lo que vale aclarar que más que dar generalizaciones a lo que sucede frente al fenómeno de la pluralización y proliferación religiosa en Colombia y su incidencia política, se pretendió profundizar en un caso, logrando reconocer los fundamentos doctrinales y teológicos que sustentan su ideología pacifista, identificar su propuesta de incidencia política y describir las estrategias propuestas en la educación para la paz, de una iglesia en particular en contraste con los planteamientos del cristianismo protestante en el país.

Para el desarrollo de la investigación se contó con la participación de ocho personas (identificadas en los resultados con la letra "E") relacionadas a los procesos de participación política por la paz miembros de la comunidad menonita. La población fue seleccionada a partir de la técnica 
"bola de nieve", la cual permite que, a partir de un contacto inicial con uno de los participantes, se pueda dar el acercamiento a otras personas que les interese ser parte de la investigación por recomendación de los mismos miembros de la comunidad estudiada. También se sometieron al análisis 11 textos (identificados en los resultados con la letra "T"), suministrados por los miembros de la Iglesia Cristiana Menonita y personal de Justapaz. La información fue analizada a partir de cinco categorías prestablecidas correspondieron a: organización eclesial, doctrina, concepto de paz, política, y educación para la paz; y seis categorías emergentes: identidad, cristianismo, iglesia, justicia, proceso de paz y territorio.

\section{Referentes de la investigación}

\section{Entre religión y política: sus apuestas por la paz}

La religión ha mantenido, históricamente, estrechas relaciones con los asuntos políticos de las sociedades; esta relación no ha sido del todo superada en lo considerado como modernidad, y en cambio sufre mutaciones gracias a la pluralización religiosa y a la diversidad política que la época implique (Bastián, 1997). Dicha relación, en ocasiones azarosa, a la luz del tema de la paz no siempre ha funcionado en pro de la construcción de paz en medio de las sociedades, incluso ha llegado a generar fuertes conflictos que desembocaron en guerras mal llamadas 'santas' o en favoritismos políticos amparados por religiones o iglesias específicas. Se pretende de este modo, develar algunas pistas de la relación religión-política, asociando sus procesos de transformación con la consolidación de la paz, argumentando que probablemente no ha sido un interés primario en dicha relación.

Löwy sostiene que el acercamiento al estudio de la religión tendrá que hacerse "como a una de las diversas formas de ideología -a saber, de la producción espiritual de un pueblo; de la producción de ideas, representaciones y conciencia, necesariamente condicionadas por la producción material y las correspondientes relaciones sociales" (Löwy, 2006, p. 283). Al acercarse a la religión cristiana, es preciso comprender que sus producciones espirituales o representación de mundo, obedece a la construcción de la historia de un pueblo en particular, el pueblo judío. Su origen se remonta en una cultura con sus propias costumbres, su legado de peregrinaje, invasiones y guerras en la que Yahvé les acompaña o no, según su capacidad de obediencia. La llegada de Jesús sucede en medio del gobierno del imperio romano. Los judíos expectantes de un mesías que restableciera el reinado de David, esperaban una confrontación armada 
contra el imperio, sin embargo, el estilo de vida de Jesús no era el de un gobernante y menos el de un combatiente, la propuesta de Jesús descrita en los evangelios, resume la Ley judía y los hechos de los profetas en "amar a Dios y amar al prójimo como a sí mismo", una propuesta pacifista donde se replantean las formas acostumbradas de relacionarse con las personas.

Con el devenir del tiempo, las enseñanzas cristianas fueron adaptándose a las condiciones sociales, culturales y políticas de las distintas épocas. Las formas actuales del cristianismo rara vez obedecen a sus formas iniciales, por ejemplo la iglesia primitiva intentando seguir las enseñanzas de Jesús resistió al imperio romano, soportó su opresión y persecución y evadió todo intento de adherirse a una guerra civil. Sin embargo y por la preocupación de la posible caída del imperio romano, este suprime su persecución y emprende algo que parecía prometedor: un matrimonio entre religión y política. Después de esto, el cristianismo pertenece a las formas de gobierno, de allí en adelante la historia del cristianismo no puede contarse sin dicha alianza: su expansión, su estabilización, su aceptación y divulgación hace parte también de las historias políticas de los pueblos que la adoptaron; como lo menciona Löwy (2006). "Primero la cristiandad fue una religión de los esclavos, luego la ideología estatal del Imperio Romano, después vestimenta de la jerarquía feudal y, finalmente, se adapta a la sociedad burguesa" (p. 285).

Existen algunos aspectos que vinculan lo religioso con lo político, en tanto que ambos hacen parte del proceso de reflexión del sentido de existencia y de relación con otros; como dimensiones que representan instituciones simbólicas de lo social, influyen en la construcción de sociedad, y en este sentido en las formas de cohabitar entre las personas. Esta relación según Hervieu, puede darse como una contaminación, un deslizamiento de lo religioso en lo político, llevando a una patología social por un proceso de destrucción y perversión, una "enfermedad" de lo político (Hervieu, 1993, p. 187). Dos ejemplos comunes del vínculo entre lo religioso y lo político son la autoridad de una tradición y la disponibilidad de creyentes; al ser la religión un aparato ideológico, tanto la tradición como la creencia son factores determinantes en el sostenimiento de la religión en sociedad, así mismo en lo político las tradiciones de las formas de gobierno, funcionan gracias a que existen personas dispuestas a creer en sus postulados y mantener dichas tradiciones. El deslizamiento que menciona Hervieu, sucedería cuando los valores de una se cruzan y en la mayoría de los casos se imponen en los valores de la otra, modificando a favor de unos, las acciones religiosas o políticas. 
Algunos sucesos en la historia del cristianismo vinculan la religión y la política con el tema de la paz, entre estos se destacan los postulados pacifistas de los anabaptistas del siglo XVI, los movimientos socialistas-cristianos; y en la historia de Latinoamérica, las mediaciones católicas por la idealización de la seguridad de estado, por mencionar algunos. Luego de la Reforma Protestante, algunos cristianos cuestionaron el hecho que se mantuvieran alianzas con los gobiernos con el fin de resguardar su permanencia, mostrando simpatía con la militarización, e incluso justificando la participación de los creyentes en la guerra bajo postulados de sumisión a la autoridad y al considerarse del lado de los buenos, ser parte de una guerra justa. Ante esto, los cristianos anabaptistas adoptaron la postura de la no-violencia, incluso en defensa de la propia vida, se resistieron a ser parte de los ejércitos que defendían sus naciones, y consideraron que el reino de Dios implicaba una sociedad sin clases sociales ni propiedad privada ni autoridad estatal (Löwy, 2006). Pusieron su énfasis en el valor de la vida, argumentando que ninguna situación justifica tomar la vida de otro, y se sustentaban en la idea de compartir las posesiones con quienes las necesitaban, una suerte de ideales socialistas que molestaba a los gobiernos de la época, quienes veían como una amenaza dichas ideas. Los cristianos anabaptistas, además, han sostenido desde entonces la idea de que la paz solo es posible desde la justicia y la equidad social, ideas que motivaron a algunos campesinos del siglo XVI hacia la revolución, pero que desbordaron sus ideas pacifistas iniciales al armarse para defenderse.

La mitad del siglo XX se caracterizó por dos corrientes que transformaron el campo religioso-político, como resultado de la unión entre las creencias marxistas-socialistas y el cristianismo: la democracia cristiana y la teología de la liberación, en ambos casos se reconoce la huella de la "aceptación" que la religión y la política funcionaban en equipo y no eran tan distantes como se pensó inicialmente. La democracia cristiana pretendía adoptar algunos valores del cristianismo para gobernar: la fe en las instituciones, la familia nuclear, la necesidad de figuras de autoridad y la primacía de la moral. La teología de la liberación por su parte, exigía la libertad de conciencia como condición necesaria para el desarrollo de la vida, la preferencia por los pobres, la reflexión en las formas de vida desde las ciencias sociales y humanas, y no solo desde la teología, y el rechazo a las injusticias sociales, argumentando que fueron estas las doctrinas básicas de Jesús. Desde esta última corriente, la paz ya no corresponde solamente a una experiencia espiritual e individual, es considerada para el cristianismo que adopta esta teología como una experiencia social y materializada en valores comunes. Un caso sobresaliente que defendió la teología de la liberación fue el sacerdote católico Camilo Torres, sus doctrinas serían luego el fundamento para grupos guerrilleros, 
bajo la premisa de llevar a cabo los valores del cristianismo desde los postulados marxistas.

En el caso de Latinoamérica, su experiencia de relación entre religión y política estuvo influenciada obviamente por la corona española; la religión católica para muchos de los países latinos, era la religión oficial que determinaba las formas de gobierno. El establecimiento de concordatos entre los Estados y la Iglesia, pretendía conservar el orden y regir bajo los principios del cristianismo católico, esto se vio consolidado en las constituyentes de los países y el monopolio de la educación, la cual era impartida con exclusividad de la Iglesia Católica: "la religión seguía teniendo gran influencia en la política del virreinato, porque era ella la que formaba a la burocracia del gobierno (...)" (Saavedra, 2013, p. 96). En el caso colombiano, es el partido conservador el que impulsa la enseñanza para cristianizar la población, y en su necesidad de impulsar el desarrollo, el progreso y la modernidad del país basan esta educación en la ciencia y la técnica pero impartida por religiosos (Andrade, 2011, p. 165).

Hacia la década de los 30, se evidenciaba como el hecho de que la religión católica tuviera tanta influencia en lo político, llevara a la consideración que las ideas izquierdistas, socialistas, marxistas fueran identificadas como opositoras al cristianismo, se decía que su interés era el de arrebatarle su espíritu cristiano a la población, y que por lo tanto no debían ser aceptadas ni enseñadas. Gracias a las continuas confrontaciones y a la formación cada vez mayor de sindicatos, se generaron cambios en las ideologías políticas, y la iglesia sentía que empezaba a ponerse en riesgo su influencia, dando paso a la pluralización religiosa.

En este sentido, la pluralización religiosa debe ser entendida en conjunto con la pluralización política, al tener libertad en la elección de opciones religiosas y políticas, también se abre la brecha para que funcionen con independencia la una de la otra. Parker considera que las iglesias se debaten entre tres orientaciones: "la defensa de la justicia social, o de valores morales o bien de los intereses institucionales" (Parker, 2012, p. 63). Aunque la relación religión-política ha sido una relación históricamente de conflicto, lo que podría notarse en la actualidad es que dicho conflicto va más allá de la influencia o dominio de la una sobre la otra, para orientarse hacia el creyente que en últimas es quien se encuentra permeado de ambas y con la posibilidad de elegir en el amplio espectro de las opciones políticas y religiosas. En esta transformación, la paz no es un ideal básico, por el contrario la pugna religión-política ha sido una lucha por conservarse, legitimar sus prácticas y mantener sus fieles. 


\section{La evolución del concepto de paz}

Al hablar de paz, históricamente, se ha hecho junto al concepto de violencia. No es de desconocer que la historia de la humanidad muestra desde sus inicios grandes conflictos que terminaron resolviéndose por la vía de la violencia. Incluso, con las nuevas auroras que se abrieron con el pensamiento renacentista, luego cuando se pensaba que el uso de la ciencia y la tecnología cambiaría radicalmente el curso de la humanidad, y después se atisbaba la modernidad como respuesta a las incertidumbres del hombre, estallan las guerras mundiales, dejando a las naciones con un resentimiento evidente en su preparación armamentista, su cada vez más desarrollada industria bélica y un temor generalizado por los constantes conflictos armados en diferentes lugares del mundo. En palabras de Muñoz (2001), a partir de los indicadores sociales, políticos, económicos y ambientales la humanidad se ubica en el momento más violento de su historia (p. 53).

En las relaciones humanas y dadas las enormes diferencias entre cada habitante de una sociedad, surge el conflicto. Galtung (2003) distingue el conflicto de la violencia; los conflictos han estado presentes en toda la historia de la humanidad, el autor los define como inherentes a todos los sistemas vivos, ya sea como fuerza para el cambio, o como metaconflictos, es decir, cuando se convierten en violencia (Calderón, 2009, p. 61). Además, el conflicto está relacionado con la complejidad en que la vida humana sucede, dado que cada individuo es en sí mismo un universo complejo, y que las relaciones con los demás se mantienen dentro de un estado de complejidad, el conflicto se convierte en una cualidad inherente a las personas; "forma parte del proceso de interacción social en el que los intereses de los individuos y grupos se interaccionan, se regulan, transforman o resuelven en ocasiones. (...) es una parte esencial del complejo desarrollo de socialización que experimenta toda entidad humana en su trayectoria" (Muñoz, 2001, p. 37).

Galtung distingue tres dimensiones que construyen una definición del concepto de conflicto: las actitudes, que corresponderían al aspecto emocional, cómo sienten y piensan los involucrados en el conflicto, la percepción de sí mismo y del conflicto como tal; el comportamiento, que corresponde al aspecto objetivo, se refiere al cómo actúan las partes del conflicto, sus intereses y reacciones; y la contradicción, que corresponde al aspecto subjetivo, donde se incluye el tema del conflicto y cómo se manifiesta (Calderón, 2009, p. 69). De esta manera, el conflicto tiene siempre diversos aspectos que afecta su transformación, los cambios que 
las relaciones humanas conllevan, representan nuevos retos y cambios permanentes que no siempre son resueltos en los mejores términos.

La violencia aparece entonces como la ausencia de transformación apropiada de los conflictos, cuando la force motrice que indica Galtung, se orienta hacia los metaconflictos, entonces se genera la violencia la cual puede ser entendida como un fracaso en la trasformación de los conflictos, cuando aquello que pudo usarse para hacer construcciones conjuntas, fue usado para hacer destrucciones masivas, y cuando se pierde de vista el conflicto como oportunidad; para Galtung (2016): "La violencia puede ser vista como una privación de los derechos humanos fundamentales, en términos más genéricos hacia la vida, eudaimonia, la búsqueda de la felicidad y prosperidad" (p. 150). La violencia en cualquiera de sus formas muestra las propias ausencias de los seres humanos, y su incapacidad o su desinterés en transformar los conflictos.

Los estudios sociales en la búsqueda de la paz han construido toda una línea de investigación en perspectiva violentológica, es decir, el punto de partida de sus estudios no fue la paz en sí misma, sino mejor que el concepto de paz se estudió junto al concepto de violencia. Antes de las guerras mundiales, el concepto de paz no gozaba de un estatus científico como el que se evidenció luego que estas ocurrieran. Algunos autores han reconocido que en los inicios de la historia de la humanidad se puede decir que la misma idea de paz no era necesaria, en tanto que no existía tal horizonte preocupante y que las sociedades estaban mayormente interesadas en llegar a acuerdos para mantener un equilibrio entre las personas que hacían parte de sus grupos sociales. Con lo ocurrido en la Segunda Guerra Mundial, se pierde tal búsqueda de equilibrio, y empieza a surgir el interés por los estudios para la paz.

Siguiendo a López (2011), se podrían reconocer tres etapas fundamentales en los estudios sobre la paz que han orientado los conceptos y el tratamiento de esta: un primer momento correspondería al ubicado entre 1930 a 1959, cuando el concepto de paz está supeditado al de violencia, hay un enfoque violentólogo para la investigación, por lo que la paz se concibe como ausencia de violencia directa, a este período se le podría atribuir el concepto de paz negativa. Un segundo momento se ubica entre los años 1959 a 1990, cuando gracias a la creación del Instituto para la Paz de Oslo, con la dirección del investigador Johan Galtung, el concepto de paz se proyecta ahora no solo desde la ausencia de la violencia, sino como un asunto de justicia y desarrollo para suplir las necesidades humanas de seguridad, bienestar y libertad, por lo que prima el concepto de paz positiva. En términos de Bonilla, a este punto las dos principales 
acepciones para el concepto de paz: "sería concebida al mismo tiempo como ausencia de violencia personal, llamada 'paz negativa', y ausencia de violencia estructural, también conocida como 'paz positiva' y asimilada como 'justicia social”' (Bonilla, 2016, p. 214).

El tercer momento viene desde 1990 y hasta la actualidad, es el que permite la introducción del concepto de cultura de paz, poniéndose la paz en una posición central, no vista ya desde la violencia o desde la justicia, sino mejor como un asunto propio de las culturas y de la diversidad que esta implica; se está básicamente bajo el concepto de paz imperfecta, donde la educación y la comunicación serán las principales herramientas para su generación. En este sentido hablar de paz imperfecta implica una renovación constante de las ideas en torno a la paz y un concepto más amplio sobre esta, poniendo en la mesa las formas pacíficas para la resolución de los conflictos, esto "lleva a pensar en la posibilidad de una paz imperfecta revelada como una paz dinámica y perennemente inconclusa apoyada en diversos actos regulativos, transformadores y cotidianos" (López, 2011, p. 9).

La investigación para la paz dio como resultado la dinamización de las ciencias, en especial las ciencias sociales, valiéndose de estrategias como la interdisciplinariedad y el tratamiento cercano a los problemas que conllevan las relaciones sociales; es además un campo de transdisciplinariedad que retoma los fenómenos sociales desde una perspectiva plurimetodológica. Durante el siglo XX, como resultado de la toma de conciencia del papel prioritario de la paz, se da apertura a hablar de la cultura de paz (Muñoz y Molina, 2010, p. 45); esta nueva mirada da como fruto el estudio para la paz desde la paz, tratando en encontrar las claves en que está escrita una cultura pacífica, una paz por medios pacíficos como titula su obra Johan Galtung (2003). Esta perspectiva implica un cambio paradigmático, donde la paz puede, en este sentido, ser aprendida y enseñada, además de establecer la coherencia entre los medios y los fines, algo de lo que Gandhi ya había promovido con su frase "No hay camino para la paz, la paz es el camino", así la paz deja de ser el fin último que justifica la guerra para ser alcanzada; pasando de fin a medio las acciones no violentas resuenan como garantías de una paz imperfecta y no como un estado de idealización de la paz.

La paz imperfecta surge entonces como respuesta a la concepción de que la vida humana sucede y se desarrolla en medio de complejidades, de condiciones de inestabilidad y dinamismo, de constantes cambios y conflictos a los que está propensa; incluso el conflicto puede ser 
considerado como necesario en el proceso de socialización, que pone en evidencia la diversidad humana y su relación con los otros y su medio, que direcciona y regula las interacciones, es por esto que la cultura de paz se basa en aquellas realidades humanas, y se vale del concepto de paz imperfecta para "(...) definir aquellas instancias en las que se pueden detectar acciones que crean paz y las interacciones entre ella, a pesar de que estén en contextos en los que existan los conflictos y la violencia y, por lo tanto, convivan con ellos" (Muñoz y Molina, 2010, p. 51). Es decir, se entiende una paz imperfecta por la consideración que en las interacciones humanas existirán conflictos y que dichos conflictos pueden ser mediados a través de acciones no violentas, sin poner a la paz como fin último sino como medio de transformación y, en muchos casos, superación del conflicto.

La paz imperfecta no desestima la paz negativa o la paz positiva: las paces en sus diversas acepciones, por el contrario, las retoma, en tanto que se constituye en un insumo teórico para reconocerlas e interrelacionarlas, sin embargo las supera en la idea de concebir la paz con infalible o utópica, algo demasiado alejado de las realidades humanas, por esto la paz imperfecta está pensada para las manifestaciones y prácticas pacíficas sin desconocer desde unas medidas incompletas la presencia pasada, actual o futura de los conflictos. De allí su nombre, la cultura de paz no asume el riesgo de la perfección y de la exactitud en la resolución de los conflictos, habrá siempre alguna situación que impida completar acciones y procesos pacíficos, y eso se debe básicamente a la condición humana de quienes asumen dichas acciones y procesos.

Esta idea de construcción de espacios para gestionar la paz o de habitus (Muñoz y Martínez, 2011, p. 58), requiere de la superación del esquema de que los seres humanos son violentos o pacíficos por naturaleza, para trasladarse a la postura que las personas pueden y requieren aprender y enseñar formas pacíficas de convivencia, resolución o transformación de los conflictos y habilidades prosociales. A las acciones anteriores se les conoce con el nombre de empoderamiento pacifista, como esa capacidad de las personas para construir redes de apoyo que trabajan en pro de objetivos comunes, basándose en las realidades sociales que resultan de la violencia o de los conflictos no superados positivamente para reconocerlas, actuar y transformar su campo de acción. Desde una perspectiva de paz imperfecta, podrá entenderse como la construcción de la cultura de paz sucede allí, en espacios comunes de participación ciudadana. 


\section{La orientación pacifista en el cristianismo anabaptista menonita}

Los primeros anabaptistas se conocieron como el "ala radical" de la reforma protestante; esta radicalidad estaba relacionada con su énfasis puesto inicialmente en contra del bautismo de infantes (en su lugar, el bautismo en la edad adulta), la separación iglesia-Estado, la objeción de conciencia y su orientación a la no-violencia. Estas cualidades marcaron trascendentalmente su distinción con el resto de los protestantes, quienes en sus inicios compartían aún los preceptos de la iglesia católica, en especial su necesidad de ser validada por el Estado. Sin embargo, en cuanto a la doctrina los anabaptistas menonitas, aunque puedan tener algunas diferencias, comparten y dan por válida la teología protestante o evangélica: "la creencia en un único Dios, la Trinidad, la encarnación de Jesucristo, la necesidad de salvación para los seres humanos, la gracia, la esperanza de resurrección de los muertos, y las Sagradas Escrituras como guía de conducta del cristiano" (Cristianismo menonita, s.f.).

Como legado del imperio romano a cargo de Constantino I o Constantino el Grande, el cristianismo en Europa se había expandido, distanciándose mucho de lo que los cristianos de los primeros siglos habían creído y vivido. Al ser la religión cristiana la oficialmente establecida por el imperio, el énfasis del cristianismo dejó de ponerse en las experiencias personales de conversión para situarse en la expansión del imperio a través de la construcción de grandes catedrales y la imposición de sacramentos (Becker, 2008, p. 6); por lo que los cristianos consideraron haber cumplido ya con la Gran Comisión que Jesús les había encomendado, es decir, la evangelización del mundo. La Reforma Protestante y la Reforma Radical, principalmente revelaron que dicha evangelización mundial aún no se había cumplido, y que por el contrario el cristianismo había caído en una religiosidad que distaba de lo que la Biblia indicaba, y se había reemplazado por preceptos organizacionales, los cristianos anabaptistas se oponían a esta concepción de cristianismo "creían que cada persona debía decidir si se comprometería a una relación personal y voluntaria con Jesucristo (...) consideraban que el poder real no residía ni el magistrado ni en la iglesia territorial" (Becker, 2017, p. 100).

Aunque los cristianos anabaptistas menonitas consideran que las autoridades civiles, militares, legislativas y judiciales son parte del orden que Dios ha establecido en la humanidad para la coexistencia, comprenden que se les debe obedecer hasta donde el discipulado cristiano lo permite, como lo expresa el siguiente texto publicado por la Red Menonita de Misión: 
La obediencia a las leyes no significa que se las acatará ciegamente. Ya que nuestra lealtad es a Jesús y al reino de Dios, habrá ocasiones en las que será necesario desobedecer al estado cuando sus leyes contradigan las enseñanzas y el espíritu de Jesús. (Becker, 2008, p. 8)

Además, los cristianos menonitas consideran que el discipulado cristiano también implica la separación con el mundo, de modo que no debe la iglesia adherirse a las formas de la cultura de las naciones, ni nacionalismos ni costumbres ni valores ni xenofobias o racismos, por lo que comprenden su existencia como la de un extranjero que debe trabajar en hacer el bien y ocuparse en la oración mientras dura su estadía.

En cuanto a la interpretación de la Biblia como Sagradas Escrituras, los cristianos anabaptistas consideran que "las Escrituras son inspiradas pero no son literalistas estrictos" (Becker, 2008, p. 7); esto implica que las enseñanzas menonitas se sean filtradas por las enseñanzas de Jesús, poniendo al Nuevo Testamento por encima del Antiguo Testamento, y a los evangelios por encima de los demás escritos apostólicos del Nuevo Testamento, cualquier duda que pueda surgir o aparente contradicción entre un pasaje bíblico y otro, es resuelto a la luz de las palabras de Jesús.

Para los cristianos anabaptistas, el asunto de la salvación implica un cambio de vida y conducta, ideas que se conecta con el tema de la reconciliación: una reconciliación con Dios, las personas y el entorno. La reconciliación parte de comprender los conflictos como una cualidad inherente a las relaciones humanas, por lo que históricamente los anabaptistas estuvieron en desacuerdo con las formas católicas o protestantes de disciplinar a los que se veían involucrados en algún caso de desobediencia o desacuerdo: "Aunque admitían que los Gobiernos seculares podían utilizar la espada para resolver las disputas, rechazaban la tortura, el encarcelamiento y la muerte como formas legítimas de disciplinar" (Becker, 2017, p. 107); en este sentido, el conflicto es visto como una condición que merece especial atención y no basta con disciplinar a los infractores de las leyes o de diversa opinión, sino hay un proceso de acompañamiento y reparación de los daños que se causaron.

Desde esta perspectiva argumentan su rechazo completo a la violencia, aunque hubo un suceso violento en la historia de los anabaptistas radicales quienes se levantaron para tomar la ciudad de Münster por la fuerza en los años 1534 a 1535, esto concluyó en que dicho grupo terminó separado por sí mismo del resto de anabaptistas, luego que el gobierno de la época recuperara el control de la ciudad, el resto de los anabaptistas se opusieron a las actitudes que tomaron estos radicales y formalizaron su 
orientación de no-violencia en cualquiera que fuere el caso. Toman como sustento a su orientación pacifista no-violenta la vida de Jesús, argumentando que se negó a tomar posiciones de autoridad tanto militares como gubernamentales cuando sus seguidores así lo propusieron, evidenciando en su estilo de vida el rechazo a los actos de violencia con las personas; incluso señalan que en todo discipulado o clase a la membresía de una iglesia, debería ser requisito enseñar la no-violencia y la paz; en palabras de Becker, los anabaptistas: "Rechazan participar en la violencia, pero están dispuestos a hacer aun más de lo que el estado les pida para trabajar por la paz" (Becker, 2008, p. 109).

Esta concepción de la no-violencia nació básicamente en oposición a los postulados de San Agustín frente a la llamada "guerra justa", quien intentando justificar que los cristianos participaran en la guerra, estableció algunas cualidades que determinarían cuándo una guerra podría estimarse como justa y por lo tanto ser partícipes de hechos bélicos que parecieran razonables, como la defensa enérgica de la fe cristiana frente a sus enemigos. Sin embargo, los anabaptistas consideraron que ninguna podría estimarse una causa justa para una guerra, que la violencia de ninguna manera es el medio para conseguir la paz, y que el cristianismo implica vivir al estilo de Jesucristo y no en las condiciones que imponen las culturas violentas, aunque sean aprobadas por los demás y consideradas válidas.

Los cristianos anabaptistas no solo se ven a sí mismos como pacifistas, es decir quienes rechazan la violencia, sino además al considerar que en muchas ocasiones el pacifismo resulta pasivo frente a los conflictos sociales, los anabaptistas se proyectan como constructores de paz por lo que "su objetivo es promover la revolución pacífica al abordar las desigualdades, manifestar compasión e implementar programas de justicia restauradora que transforme a los enemigos en amigos" (Becker, 2017, p. 124); es por esto que como objetores de conciencia activos, se oponen a prestar servicio militar pero crean alternativas a este, trabajando por la justicia y el cambio social, a lo que han llamado un servicio social.

La orientación pacifista de los anabaptistas se ve reflejada en algunas estrategias y programas que han diseñado en diferentes lugares del mundo, interviniendo a favor de la resolución de los conflictos y fomentando el desarrollo de las propuestas para la paz, como se demostró en el proceso de paz llevado a cabo en Colombia, los anabaptistas menonitas fueron enfáticos en su posición favorable frente a los acuerdos por la paz en el 2016 y en adelante, y con programas de mayor permanencia como lo es Justapaz entre otros. 


\section{Resultados y conclusiones}

La iglesia menonita en su apuesta por la paz y dentro de sus propuestas litúrgicas ha promovido celebraciones como los días de acción y oración por Colombia o la celebración del día internacional de la no-violencia y cese al fuego (T. 3); intentando a través de éstas manifestar una postura de no-violencia, y su compromiso por la construcción activa de la paz. Sin embargo, como lo dejan leer en sus publicaciones, estas celebraciones "generaron debate dentro de las iglesias porque faltaba más discernimiento frente al rol de la iglesia" respecto al tema de construcción e incidencia por la paz (T. 3), por lo que la actitud crítica frente a los propios procesos como iglesia los ha llevado a generar estrategias de participación política en la construcción de paz del país. Como se verá a continuación, la conceptualización de paz que proponen se asocia con el hecho de incidir políticamente desde una postura no partidista, y el trabajo desde las iglesias a través de su participación en el territorio o localidad.

Con la constituyente de 1991, se da paso a la pluralidad religiosa en el país. Gran número de las iglesias cristianas protestantes se cuestionaron acerca de cuál debería ser su participación política, por lo que muchas decidieron adherirse a partidos específicos o consolidarse en uno solo y hacer parte activa de las decisiones políticas del país, para el caso de los menonitas no fue así dado que "las iglesias anabaptistas tomaron distancia de estos espacios" (T. 3). Desde entonces, la Iglesia Cristiana Menonita se ha caracterizado por comprender la incidencia política más allá de lo partidista o lo electoral.

El asunto de la incidencia política para los anabaptistas no se constituye como una directriz de las autoridades eclesiales, sino mejor en concordancia con una tradición anabaptista de separación iglesia-Estado, en el sentido que no pueden coordinarse como asuntos que se pertenecen mutuamente, haciendo alusión a su legado histórico se menciona:

Con el establecimiento del Cristianismo como religión oficial en el siglo IV, todo cambió. Se perdió el concepto de obediencia a Dios y la iglesia acepta al César como portavoz de Dios. Sin embargo, siempre han existido comunidades de resistencia que han replanteado este tipo de relación. (T. 3)

Para los menonitas, la línea que separa hacer proselitismo político e incidencia política es demasiado delgada, tanto que a menudo cuestionan 
el hecho que el cristianismo cruce sin precaución la línea ya sea por las pasiones partidistas o los procesos electorales.

Respecto a la incidencia de la iglesia en la política se dice: "a la hora de entrar a escenarios políticos debe entrar como cualquier otra comunidad, y es respetando los procesos democráticos" (E. 3). Los menonitas entienden que su participación política no comparte las mismas intenciones que las de las iglesias neopentecostales, incluso cuestionan este tipo de participación, porque no siempre corresponde a un ejercicio de concienciación frente a los resultados de estar a favor de un partido político: "los grupos neopentecostales hacen política directa, por ejemplo hace poco en uno de sus cultos no hubo predicación sino un video de Miguel Uribe y Zuluaga" (E. 8); de este modo se promueve un sesgo político en los feligreses y sus decisiones electorales estarán determinadas por la influencia de sus líderes religiosos, lo que para los menonitas corresponde a un pecado, por no respetar la libre conciencia de los creyentes (E. 8).

Otra idea que han desarrollado los menonitas es comprender la política como condición inherente a las comunidades; es de recordar que las iglesias pentecostales tradicionalmente mantuvieron una postura apolítica, de modo que satanizaban la participación en escenarios de incidencia política y restringían el ejercicio democrático al sufragio; en contraste, iglesias históricas como los anabaptistas consideran que "cualquier hecho que haga una persona en esta sociedad es un hecho político, incluso no opinar es opinar, es hacer algo políticamente" (E. 3). Además, se sustentan en la idea que Jesús mismo tuvo incidencia política sin ser ese su interés superior, por lo que se supone que no es ausentándose de la política lo que les mantendrá a salvo del peligro, ni integrándose a cargos o partidos políticos lo que les permitirá incidir en la sociedad: "la solución no es buscar estar en cargos políticos ni buscar elegir 'cristianos' a todos los cargos políticos. La política partidaria es una forma de incidir y tal vez puede ser válida bajo ciertas condiciones, pero es un mecanismo que tiene muchos riesgos" (T. 3).

En el caso de los menonitas incluso han recibido señalamientos de otros grupos cristianos por sus preferencias políticas, les han llamado cristianos de izquierda o cristianos guerrilleros (E. 3), y no precisamente porque lo sean, aunque algunos de los participantes manifestaron su preferencia por las propuestas de partidos izquierdistas, sino porque su conceptualización de la política está orientada a la valoración de la vida, y como se hizo notar anteriormente hacia la superación de la violencia como forma de resolución de los conflictos, ideas que no compaginan con 
las propuestas de muchos de los partidos de derecha, que son los que mayor apoyo han recibido de las iglesias cristianas en Colombia.

Los menonitas parten de sus bases teológicas y doctrinales sustentadas en la ideología pacifista de Jesús, pero consideran que sus principios cristianos no deben ser impuestos al resto de la población como proselitismo religioso "como iglesia no somos una comunidad o una institución del estado que se encarga de la moral o la ética o de rescatar los valores cristianos positivos de la antigüedad, esa no es nuestra actividad política, de hecho eso es una equivocación porque nuestro estado es un estado democrático" (E. 3). Con esta acotación, es fácil entender por qué los menonitas pueden participar de espacios políticos con posturas menos conservadoras, y se cuidan de caer en juegos partidistas en tiempos electorales, evitando la polarización y la pérdida del sentido común (T. 11).

Si no es evadiendo la responsabilidad ni adhiriéndose a partidos, la forma en que los menonitas pretenden incidir en la construcción de paz del país, valdría la pena especificar en qué consiste su propuesta de incidencia política, parte de esta argumentación se encuentra en el apartado dedicado al tema de educación para la paz. Los menonitas entienden que como latinoamericanos se ha soportado el imaginario que las soluciones a los problemas sociales vienen de las personas que ocupan cargos en el poder público, "los políticos son nuestros salvadores, los señores del pueblo, solamente desde ellos se pueden resolver situaciones y no es así, hay que invertir el pensamiento, solamente desde el pueblo se puede transformar la política" (E. 1). Bajo esta premisa, los menonitas han desarrollado la idea de una política desde abajo, y más específicamente desde el territorio, a través del empoderamiento de las comunidades de fe y sus sectores de influencia, de modo que el trabajo de formación empiece en ellos y provoque efectos en la sociedad a la que pertenecen, por lo que creen en que "el rol de la iglesia en términos políticos es ser parte de la población civil pero activos" (E. 3).

Esta comprensión de incidencia radica en la conceptualización de la paz; cuando la paz se reduce al bienestar de solo una cierta parte de la población, entonces es posible creer en guerras justas o santas, o en una paz que depende de las decisiones de los que hacen la guerra como "lo que está proponiendo el centro democrático, creen que la paz simplemente se hace entre los armados (E. 5). Una paz vista desde el poder de lo comunitario invierte las funciones de la población, otorgándole el poder de intervenir en sus rumbos y cuestionarse los propósitos que subyacen en las formas de gobierno. Como los menonitas comprenden la capacidad de influencia que pueden tener en los miembros de su 
comunidad, usan como medio de protección el abstenerse de hacer proselitismo político, y el apoyar abiertamente a candidatos en tiempos de elecciones, incluso cuando quien se postula es un cristiano: "si un candidato es cristiano, se ora por él pero no se le hará campaña desde la iglesia, se espera que actúe en función de sus principios cristianos" (E. 3), pero no hay seguridad en eso porque es difícil ser cristiano y estar en la política de forma correcta, es mejor en ese caso hacer un ejercicio de veeduría y exigibilidad de derechos (E. 5).

Algunas oportunidades en las que se considera favorable la participación de las iglesias cristianas, están relacionadas con defender situaciones como la distribución de tierras, la no privatización del agua, el cuidado medio ambiental y uso de los recursos naturales, y la libertad de conciencia incluida la libertad de culto, es decir, cuando la participación política va más allá de lo electoral, del sometimiento de insurgentes o del posicionamiento de un candidato (E. 8). Sin embargo, y dado que los menonitas participan en los procesos electorales del país, han diseñado un listado de algunos principios cristianos que se deben considerar a la hora de ejercer el voto, entre los que se destacan: la proposición de soluciones no-violentas al conflicto, la reconstrucción del tejido social, la reducción de la inequidad en la repartición de la riqueza, la igualdad de oportunidades y equidad de género, alternativas para equilibrar los intereses económicos y de desarrollo, la mejora al servicio de salud, mayor inversión en educación, y la consolidación de la justicia restaurativa. Todas estas condiciones que se esperan sean tenidas en cuenta por los votantes, tienen bases doctrinales, es decir, responder a una forma particular de comprender las exigencias de Dios a la humanidad (T. 3).

Como el poder o la autoridad son actitudes propias al ejercicio político y constituye un detonante para la generación de conflictos (T. 5), los menonitas han desarrollado también una postura crítica frente a esto. Los cristianos en general se han caracterizado por defender la idea de someterse a las autoridades civiles, los menonitas por su parte consideran que "el cristiano se somete al gobierno, pero ejerce su propio juicio moral. Dios quiere que haya gobierno humano, y las autoridades públicas contribuyen a la intención de Dios en la medida que contribuyan al bienestar de toda la humanidad" (T. 3). Así que la condición para el sometimiento es que se esté llevando a cabo un gobierno en función de lo que Dios espera, es decir, el bienestar común. Por esto, los menonitas más que estar en contra de la institucionalidad, se atreven a cuestionarla cuando no está funcionando bien (T. 11) y a exigir el restablecimiento de los derechos (T. 1), porque el guardar silencio corresponde a contribuir con la validación de la violencia y el miedo (T. 3), o a caer en el error de creerse buenos cristianos 
al respetar las leyes, aunque estas sean injustas o vayan contra la vida (E. 3), por lo que ante el ejercicio político se cree que:

Es un ejercicio colectivo, y se respetan las autoridades como dice la biblia, sin sacrificar el ejercicio profético que tanto Jesús y muchos otros tuvieron el valor de decirle a los gobernantes, usted no está haciendo lo correcto, usted está oprimiendo al pueblo, usted no está haciendo su deber. (E. 5)

La forma de incidencia política que han propuesto los menonitas considera el hecho de cuestionar las formas violentas en la búsqueda de la paz, proyectarse una construcción de paz que supere lo gubernamental, impulsar la consolidación de una democracia desde las bases del pacifismo y el bienestar común: "Es preciso que la paz sea política de Estado y expresión social para la profundización y ampliación de la democracia y la vida digna para todas las colombianas y los colombianos" (T. 10). $\mathrm{Su}$ propuesta también implica formar de tal manera que las personas se responsabilicen de sus decisiones electorales (E. 8), superando el reduccionismo partidista (T. 11), y actuando desde la creencia que "como cristianos debemos votar, como cristianos debemos marchar si vemos cosas que están mal hechas, como cristianos debemos trabajar en pro de la justicia y de la paz, de la no-violencia, como cristianos debemos ser parte activa de una sociedad" (E. 2).

Así, los menonitas consideran que no es posible sacar a la religión de la política, porque en la historia de la humanidad siempre se han contado juntas (E. 3). Sin embargo, es posible aportar a la separación iglesia-Estado, en tanto la iglesia no se constituya en escenario partidista o electoral, sino mejor como un espacio de reflexión, debate y crítica a las políticas que afectan a la población y el entorno; su propuesta es incidir en la política desde la localidad, el territorio, y en sus palabras, hacer política desde abajo.

El proceso investigativo desde donde se toman los resultados permitió reconocer cómo en Colombia el asunto de la secularización no es un hecho dado, por el contrario, las relaciones entre la religión y la política no tienden a la extinción sino a la mutación. Los fenómenos de proliferación religiosa y pluralización de la fe, no son ajenos a la incidencia y participación política en el país, por lo que estudios que aborden esta relación permitirán comprender los efectos de dichas alianzas. En el caso de los menonitas, se pudo notar que el problema de la alienación a las políticas, está estrechamente relacionado a la forma cómo se interpreta el cristianismo y se proyecta a la sociedad, y que un ejercicio consciente y 
reflexivo de las prácticas religiosas, podría favorecer el alcance de objetivos comunes al país, como lo es el asunto de la paz.

\section{Referencias}

Andrade, M. (2011). Religión, política y educación en Colombia: La presencia religiosa extranjera en la consolidación del régimen conservador durante la Regeneración. HiSTOReLo. Revista de Historia Regional y Local, 3(6), 154-172.

Barrio, I., González, J., Padín, L., Peral, P., Sánchez, I. y Tarín, E. (2015). El estudio de casos. Métodos de investigación educativa. Universidad Autónoma de Madrid.

Bastián, J.P. (1997). La mutación religiosa de América Latina. Para una sociología del cambio social en la modernidad periférica. México: Fondo de Cultura Económica.

Becker, P. (2008). ¿Qué es un cristiano anabautista? Estados Unidos: Red Menonita de Misión. Becker, P. (2017). La esencia del anabautismo. Estados Unidos: Herald Press.

Bonilla, J.L. (Ene-Jun de 2016). Conflicto, religión, y educación religiosa en Colombia. Theologica Xaveriana, 66(18), 207-237.

Calderón, P. (2009). Teoría de conflictos de Johan Galtung. Revista de Paz y Conflictos, (2), 60-81.

Cedecol. (2006). Primera cumbre de la iglesia cristiana evangélica por la paz de Colombia. San Andrés

Consejo Latinoamericano de Iglesias. (2016). Iglesias presbiteriana y menonita en Colombia invitan a decir SÍ a la paz. Recuperado de https://www.justiciaypazcolombia.com/ iglesias-presbiteriana-y-menonita-en-colombia-invitan-a-decir-si-a-la-paz/

Consejo Mundial de Iglesias. (2009). Contando la paz: Historias de paz y material litúrgico para el tiempo de Adviento. Ginebra: World Council of Churches.

Cristianismo menonita. (s.f.). Anabautistas, menonitas y hermanos en Cristo. Recuperado de https://www.menonitas.org/

Deslauriers, J.P. (2004). Investigación Cualitativa: guía práctica. Editorial Papiro.

Galtung, J. (2003). Paz por medios pacíficos: paz y conflicto, desarrollo y civilización. Bilbao: Bakeaz.

Galtung, J. (2016). La violencia: cultural, estructural y directa. Cuadernos de Estrategia, (183), $174-168$.

Hervieu-Léger, D. (1993). La religión, hilo de la memoria. Barcelona: Herder Editorial.

López, M.H. (2011). Reflexiones sobre las desigualdades en el contexto de los estudios de paz. Revista de Paz y Conflictos, 4, 121-135.

Löwy, M. (2006). Marxismo y religión: ¿opio del pueblo? En: La teoría marxista hoy. Problemas $y$ perspectivas. Recuperado de http://bibliotecavirtual.clacso.org.ar/clacso/ formacionvirtual/20100720071208/12Lowy.pdf. Buenos Aires: CLACSO.

Martínez, P. (2011). El método de estudio de caso Estrategia metodológica de la investigación científica. Revista científica Pensamiento y Gestión, (20), 165-193.

Muñoz, F.A. (2001). La paz imperfecta ante un universo en conflicto. La paz imperfecta, 21-66. 
Muñoz, F.A. y Molina, B. (2010). Una cultura de paz compleja y conflictiva. La búsqueda de equilibrios dinámicos. Revista de Paz y Conflictos, 3, 44-61.

Muñoz, F.A. y Martínez, C. (2011). Los habitus de la paz imperfecta. Los habitus de la paz: teorías y prácticas de la paz imperfecta. (pp. 37-64). Universidad de Granada.

Parker, C. (2012). Religión, política y cultura en América Latina, nuevas miradas. Chile: Universidad de Santiago de Chile, Instituto de Estudios Avanzados.

Saavedra, I. (2013). Influencia de la religión en la política y su posición respecto a la configuración de la oposición política en Colombia. Derecho y Realidad, (22), 93-112. 